tion in the species. Thus for adults of Allolobophora chlorotica Sav., the distribution is normal; for Eisenia rosea Sav., it is signiflcantly
left-skew; and for Lumbricus terrestris Linn., highly significantly left-skew. In the cases of $A$. chlorotica and $E$. rosea, regeneration of the lost segments has mitigated the effect of predators on skewness, but in the case of $L$. terrestris (and two other members of this genus) but in the case of $L$. terrestris (and two other members of this genus)
regeneration of the Iost segments does not seem to occur, with the regeneration of the lost segments does not seem to occur, with the
result that the normal distribution for worms just hatched becomes result that the normal distribution for wor

Finally, the answer to the question, Do earthworms grow by Finally, the answer to the question, Do earthworms grow by adding segments?, is not the simple negative given by Sun and Pratt but rather that some species possess the adult number of
segments at hatching, in others the number of segments increases segments at hatching, in others the number of segments increases during growth and in the genus Lumbricus growth occurs in spite of a dull account of this work will be published later.

Rothamsted Experimental Station,

Harpenden, Herts. June 19

${ }^{1}$ Sun, K. H., and Pratt, K. C., Amer. Nat., 65, 31 (1931).

\section{Life-History of a Species of Metapenaeus in Australian Coastal Lakes}

THE Penæid prawns, which are the basis of a valuable commercial fishery in the warmer countries of the world including, in particular, India, Australia, the Western Pacific and the southern shores of the India, Australia, the Western Pacific and the southern

This interest is bound up with the very remarkable fact that in This interest is bound up with the very remarkable fact that in opposition to all other Decapod Crustacea (including the common prawns and shrimps af northern Europe) the Penæid prawns do not sea, where they hatch out as typical nauplius larvæ.

The existence of this primitive type of development was discovered some years ago and aroused the curiosity of zoologists, but many
years were to pass before even a moderately complete sequence of years were to pass before even a moderately complete sequence of developmental
Penæid species.

Penæid species.
Apart, however, from the scientific value of a knowledge of the Apart, however, from the scientific value of a knowledge of the
larvæ, there is another reason for making special studies of the lifelarvæ, there is another reason for making special studies of the life-
history of some of these Penæid species. To conserve any fishery it is essential to know the habits of the species concerned. The prawn fishery of the South Atlantic and Gulf coasts of the United States is the third in value of all fisheries of that eastern seaboard. The prawn industry of New South Wales, Australia, although not so valuable as that of the United States, is important, and up to a few years ago the scientiflc problem was made particularly interesting because the breeding habits of the favoured commercial species (Penous plebejus, Hesse) were completely unknown. These prawns were very rarely caught with maturing gonads, and the few I obtained with well-developed gonads came from the ocean and the seaward margin of Port Jackson, whereas the prawn fishery is only carried on inside certain estuaries and in curious coastal lakes which are often cut off from the sea altogether for a year or more at a time. Early in the year 1938, my first work dealing with the development of the well-known New South Wales commercial prawn, Pencus plebejus, was published ${ }^{x}$. It must be pointed out that our task was made rather difficult by the fact that it had to be proved first that this prawn left the estuaries and lakes and migrated to the ocean for breeding. There it was shown to increase in size to a remarkable extent as the gonads developed to maturity. This migration of Penoeus plebejus was clearly demonstrated. The different larval stages had thus to be collected at sea where the larvæ of different species can easily confuse the issue.

Later in the same year an excellent memoir by Jeanne $H$. Held ${ }^{2}$ appeared, which described more fully and definitely the life-history set free from adults in the aquarium at Salammbo and hatching and rearing took place in aquaria.

To complete the coincidence of interest in Penæid research the year 1939 brought forward a publication giving the results of at least six years work by American authorities on their commercial species ${ }^{3}$. years work by American authorities on their commercial species ${ }^{3}$. Apparently the American workers found similar migrations to the Very satisfactory series of larvæ were obtained.

In the course of our early. New South Wales investigations one In the course of our early New South Wales investigations one species of Penæid (a species regarded at the time as of little or no
importance in the flshery, and the existence of which was apparently importance in the flshery, and the existence of which was apparently
unrecognized by some fishery authorities) was caught inside the shallow unrecognized by some fishery authorities, was caught inside the shallow coastal lakes with gonads in a fair state of development. The exceptional fact was noted, but the war years prevented our obtaining any other specimens of this species at the breeding season. During led to the discovery of a fine series of the early stages but also has led to the discovery of a fine series of the early stages but also has shallow coastal lakes and breeds there.

The species (known locally as the 'greasy back') has usually been regarded as Penceopsis monoceros (Fabricius, 1798) or Metapenceus monoceros Alcock, a species of very wide range extending not only to India, but also, by migration through the Suez Canal, to the Mediterran ean. However, there are some grounds, according to Burkenroad, for regarding the 'greasy back' of New South Wales as a new species of Metapenceus ${ }^{4}$

A complete account of the life-history is being published.

Department of Zoology,

W. H. DAKIN

University of Sydney.

${ }^{1}$ Dakin, W. J., Proc. Zool. Soc., Lond., Ser. A, 108, Pt. 2 (1938) See also Dakin, W. J., Records Aust. Mus., 20, No. 5 (1940). ${ }^{2}$ Heldt, Jeanne H., Ann. l'institut oceanographique, 18, Fasc. 2 (1938). ' Burkenroad, Martin D., personal communication.
Relativity Transformations Connecting Two Systems in Arbitrary Acceleration

THE physical meaning of every term in the Lorentz transformation is now clear, thanks to the investigations of Einstein. Unfortunately, the general Lorentz transformations usually given as

$$
\begin{gathered}
\vec{r}=\overrightarrow{r^{\prime}}+\vec{v} \frac{\left.\overrightarrow{(v} \cdot \overrightarrow{r^{\prime}}\right)}{v^{2}}\left(\frac{1}{\left.\sqrt{1-\beta^{2}}-1\right)+\vec{v} \frac{t^{\prime}}{\sqrt{1-\beta^{2}}},}\right. \\
t=\frac{t^{\prime}+\frac{1}{c^{2}}\left(\vec{v} \cdot \overrightarrow{r^{\prime}}\right)}{\sqrt{1-\beta^{2}}},
\end{gathered}
$$

do not possess some of the beautiful properties of the original linear motion transformations owing to the non-group nature under successive velocity transformations and to the non-symmetry with respect to the space-time co-ordinates. I think something should be done about this.
After making clear the idea of contraction of length and clock and After making clear the idea of contraction of length and clock and
the misadjustment of the clocks, one is inclined to ask when the clocks and scales will be so contracted as the system just starts to move. Einstein did not trouble himself with this question as the system is, was and will always be in uniform motion, an idea handed down from Newton's time. It is therefore imma ierial when it contracts or when the clocks are misadjusted. Students, however, usually come to me with the question as to whether the two ends of a rigid stick contract towards its centre. This is obviously not so, for many short sticks joined end to end would leave spaces between them after contraction, a fact certainly against the principle of relativity if not logic. Also, distant sticks cannot contract instantly as soon as the system starts to move, for no velocity of signalling can be greater than the velocity of light and there does not exist a rigid body system in relativity. A very, very long stick must have an enormous velocity at its ends in order to complete this contraction within the short interval during which the system attains its final velocity! To answer such and kindred paradoxes it is necessary to go back once more to the physical principles underlying the contraction and misadjustment of the clocks in the special theory of relativity. Take, for example, the synchronizaat different places of the moving system are due to the light signal connexions between places where clocks are to be synchronized ; that is, the observers did not and could not adjust their clocks instantly. We certainly synchronize our clocks with, say, Greenwich by its constant radio signals and adjust our clocks by allowing for the time of travel. Our friends on the moving system would probably do the same thing and, being ignorant of their motion, have misadjusted their clocks I (The terms rest and motion here are only relative. But for the sake of clarity, we shall speak of a moving and a rest system as if it exists, and shall prove their relativity only afterwards.) Similarly, we flnd such effects in the apparent contractions of lengths and clocks. With this explanation, it is now possible to answer some perplexing problems encountered in Finstein's special relativity. The this thought, we can work out the effects on clocks, etc., due to this thought,

Since all the measuring standards along the light signal tracks emitted from the 'origin' of the moving system are affected similarly, emitted from the 'origin' of the moving system are affected similarly, according to the Lorents
of the 'origin', therefore

$x-\xi=\frac{x^{\prime}+v\left(t^{\prime}-\tau^{\prime}\right)}{\sqrt{1-\beta^{2}}} ; t-\tau=\frac{t^{\prime}-\tau^{\prime}+\frac{v}{c^{2}} x^{\prime}}{\sqrt{1-\beta^{2}}} ;$

where the primed letters refer to the moving system, unprimed to the rest system, and where $c(t-\tau)$ is simply the distance between an arbitrary point $P$, where the clock is to be synchronized with the origin, and the origin the velocity of which at time $\tau=t-r / c$ is $v$ and acceleration $\Gamma_{x}$. The elock at the moving origin will register a time $\tau^{\prime}=\int \sqrt{1-\beta^{2}} d \tau$ due to the successive Lorentz contractions. From them we obtain $r^{\prime} / c=t^{\prime}-\tau^{\prime}$ and the differential coefficients :

$$
\begin{aligned}
d x= & \frac{d x^{\prime}+v d t^{\prime}}{\sqrt{1-\beta^{2}}}+\frac{r^{\prime} \Gamma_{x}}{c\left(1-\beta^{2}\right)\left(1-\beta_{r}\right)}\left(d t^{\prime}-\frac{d r^{\prime}}{c}\right) ; \\
d t= & \frac{d t^{\prime}+\frac{v}{c^{2}} d x^{\prime}}{\sqrt{1-\beta^{2}}}+\frac{r^{\prime} \Gamma_{r}}{c^{2}\left(1-\beta^{2}\right)\left(1-\beta_{r}\right)}\left(d t^{\prime}-\frac{d r^{\prime}}{c}\right) ;
\end{aligned}
$$

where

$$
\Gamma_{x}=\frac{d v}{d \tau}, \Gamma_{r}=\Gamma_{x} \frac{x-\xi}{r}, \beta_{r}=\frac{v}{c} \frac{x-\xi}{r}
$$

and

$$
d \tau=\frac{d \tau^{\prime}}{\sqrt{1-\beta^{2}}}=\frac{d t^{\prime}-\frac{d r^{\prime}}{c}}{\sqrt{1-\beta^{2}}} .
$$

The interpretations of these terms are interesting, but we shall only mention some practical applications here. From these transformation 